\title{
ARQUEOLOGÍA Y RESTAURACIÓN ARQUITECTÓNICA: EL CASO DEL MONASTERIO DE SANTA MARÍA LA REAL (AGUILAR DE CAMPOO, PALENCIA) ${ }^{1}$
}

PEDRO MATESANZ VERA

Estudio de Arqueología. Madrid

\section{Resumen}

Las intervenciones restauradoras llevadas a cabo durante las últimas décadas en el monasterio de Santa M. ${ }^{a}$ la Real (ss. VII-XIX) y su repercusión en el edificio y en el yacimiento se estudian en este trabajo. El análisis arqueológico de un edificio de estas características ha requerido un tratamiento especial tanto en la excavación como en el estudio de la arquitectura del conjunto monástico.

\section{Summary}

This paper studies the restoring interventions carried out during the last decades in the monastery of Santa M. ${ }^{2}$ la Real ( 7 th to 19 th centuries) and their repercussions upon the building and the archaeological site. The archaeological analysis of a building with these features has required a special treatment in the archaeological excavation, as well as in the study of its architecture.

El monasterio de Santa María la Real se sitúa a unos $500 \mathrm{~ms}$. al oeste de la villa de Aguilar de Campoo, en el norte de la provincia de Palencia, (Fig. 1). Ubicado al abrigo de un promontorio rocoso que lo protege de los vientos dominantes del norte, junto a un caudaloso manantial que fluye del interior de dicho promontorio y en la vega del río Pisuerga, en su margen izquierda.

${ }^{1}$ El presente trabajo se presentó en el III Simposio sobre Restauración Monumental. Barcelona. Noviembre, 1992. 


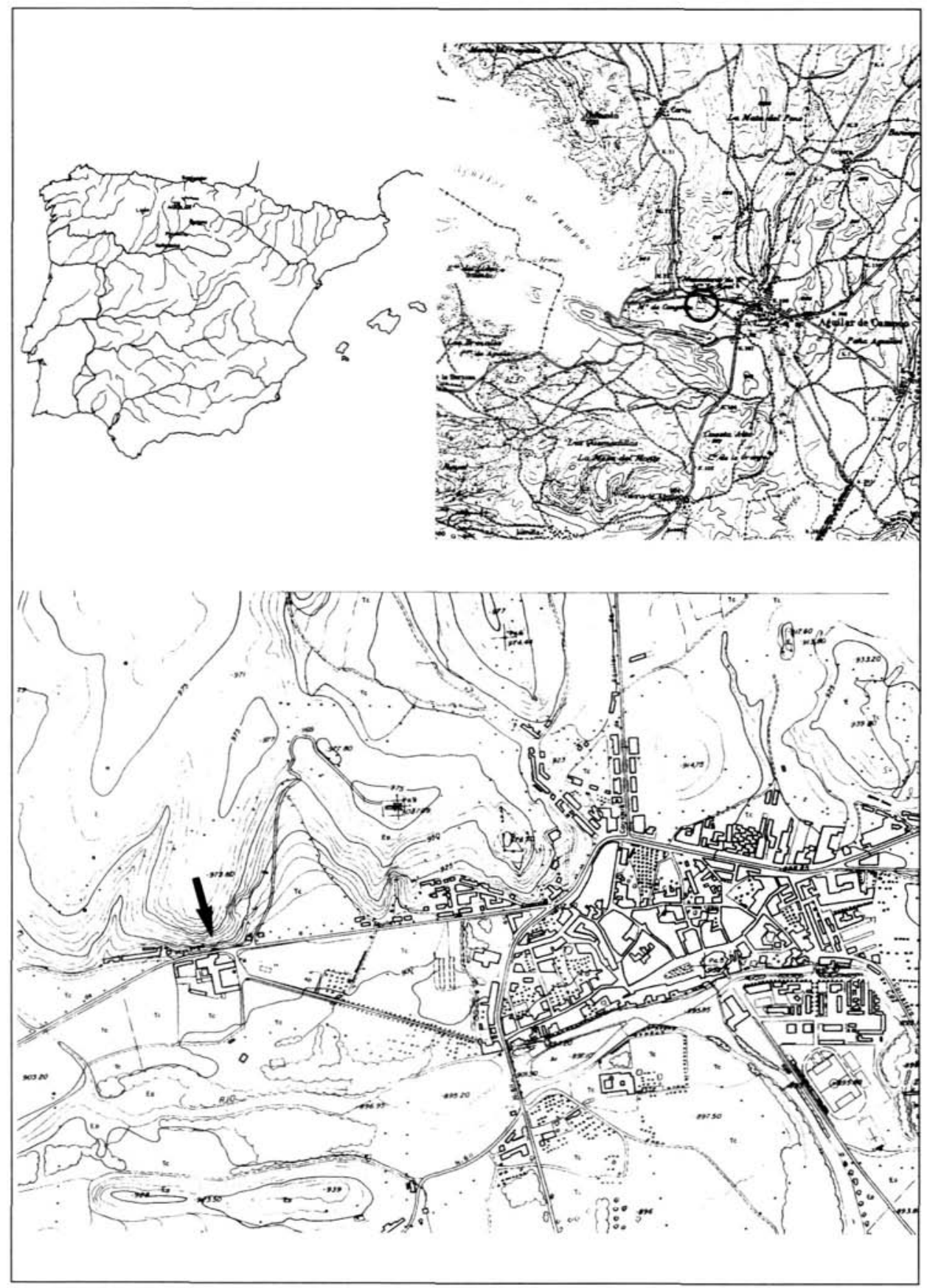

Figura 1. Mapas de situación 
Históricamente hablando, la importancia de este monasterio se atestigua por las múltiples referencias al mismo que se documentan desde el s. XI (Becerro de Aguilar de Campoo, A.H.N, 1. ${ }^{a}$ mitad s. XIII, códice 994-B) y por los numerosos trabajos realizados sobre su historia (Assas, 1872; Mélida, 1915; García Guinea, 1975; Merchán, 1982; Bravo y Matesanz, 1986; y más recientemente, González de Fauve, 1992).

El monasterio de Santa María la Real, remonta sus orígenes al s. VII, al menos, así lo indican los últimos datos aportados por las excavaciones arqueológicas ${ }^{2}$, llevadas a cabo desde 1978 hasta 1991 (1978, director L. Caballero; 1979 a 1981, directores M. Retuerce y P. Matesanz; y desde 1982, P. Matesanz).

Documentalmente la referencia más antigua, datada en el año 852 , la encontramos en la escritura de fundación (Becerro de Aguilar de Campoo, A.H.N., 1. ${ }^{a}$ mitad s. XIII, códice 994-B, fols. 1 y 2 v.). En dicho documento se narra que el abad Opila, ayudado por un rico caballero, llamado Alpidio, y seguido por un grupo de clérigos, encontró en 822 dos iglesias abandonadas en las que fundó un monasterio. El conjunto al que se refiere este texto (que, por otro lado, ha sido considerado falso por diversos autores [Backmund, 1956: 237; González de Fauve, 1992, 51-52, 71-73; Merchán, 1982, 40; véase, para más referencias bibliográficas, Bravo y Matesanz, 1986, 13]) sería anterior al que debemos suponer que ya existe en 1039. De este año es la primera noticia documental clara sobre la existencia del monasterio [A.H.N., Sección Clero-Pergaminos, Carpeta 1647, doc. n. ${ }^{\circ} 1$ : La Condesa Doña Ofresa dona su heredad con sernas, tierras, viñas, solares, molinos,..., por su alma y para que su cuerpo sea sepultado en el Monasterio]). Aunque la fecha sostenida en el documento del año 852 se tenía por dudosa al ser considerado como falso el texto en cuestión (Bravo y Matesanz, 1986, 13 y 14), los últimos datos arqueológicos confirman un nivel de época visigoda (finales del s. VII), además de estructuras claramente previas a lo románico del s. XII, que a priori nos estarían llenando ese vacío documental entre el s. IX y el s. XI; dentro de este espectro cronológico se situaría el conjunto referido en el documento de 1039.

A partir de mediados del s. XI hasta comienzos del XII se constata una gran laguna en la documentación, con sólo dos textos, de 1103 y 1112 (Becerro de Aguilar de Campoo, A.H.N., $1 .^{a}$ mitad s. XIII, códice $994-B$, fols. 6 v., 7 r. y 7 v.; y 10 v., respectivamente), y de nuevo otro vacío hasta la mitad del mismo s. xII. La mayor parte de los documentos son referentes a donaciones de particulares al monasterio de Santa María de Aguilar.

La documentación no es muy precisa con respecto a la situación del monasterio con anterioridad a la instalación en el mismo de los premonstratenses, ni en lo referente a cuáles fueron sus anteriores ocupantes (Merchán, 1980, 27) ni en cuanto a su nivel económico y de desarrollo. No obstante, hay datos que nos indican que era un monasterio

${ }^{2}$ Las excavaciones arqueológicas han sido financiadas por el Ministerio de Cultura (1978-1983) y por la Junta de Castilla y León (1984-1991). 
floreciente y que gozaba del favor real. Entre 1069 y 1155 (fundamentalmente bajo Alfonso VII) se producen las primeras donaciones y privilegios reales. En esa época, la monarquía aparece como elemento protector de la institución monástica concediendo a la misma privilegios (carta de asentamiento, derechos de tránsito sobre las diferentes vías que rodean el monasterio, privilegio de coto, derechos de pesca en todo el término de Aguilar, derecho a poblar la zona, etc.) y exenciones, como la de pago del portazgo (Merchán, 1982, 43). Asimismo, dotará institucionalmente al monasterio con mecanismos jurídicos de protección y defensa, lo cual supone el comienzo del gran dominio territorial de Aguilar que conocerá su momento álgido con la llegada de los premonstratenses (Merchán, 1982, 44).

La nueva orden se instala en Castilla (concretamente al norte del Duero) bajo el reinado de Alfonso VII y con el favor de algunos nobles. Es una época, la segunda mitad del siglo xII, en que se imponen órdenes monásticas de reciente creación con la subsiguiente decadencia de las comunidades más antiguas (Merchán, 1982, 45-46). En 1146 fundan el monasterio de Retuerta donde establecen su "casa madre", desde la cual la orden empieza a extenderse. En 1152 el rey Alfonso VII dona al abad de Retuerta el monasterio de San Agustín (Herrera de Pisuerga, Palencia), con lo cual éste se convierte en una abadía premonstratense (Bravo y Matesanz, 1986, 14-15). La fundación no prospera y los premonstratenses ponen sus miras en Santa María de Aguilar para ubicar allí a la comunidad procedente de Herrera. Para poder realizar semejante trasvase, en 1169 el rey Alfonso VIII cede a Retuerta sus derechos sobre Santa María y sus coherederos donan al abad de la Regla de San Agustín el propio monasterio de Aguilar. Así, con esta doble cesión, el monasterio de Santa María de Aguilar pasa a pertenecer a la Orden Premonstratense (Merchán, 1982, 57).

La ocupación definitiva no se llevará a cabo hasta 1173 , puesto que, tras los acuerdos de 1169 , los antiguos ocupantes del monasterio, resistiéndose a abandonarlo, recurrieron al legado pontificio. El conflicto se concluye mediante concordia con la promulgación de la Bula del Cardenal Jacinto, lo que supuso la instalación final de los premonstratenses en Aguilar (cuyos abades se suceden hasta la Desamortización) (Bravo y Matesanz, 1986, 15-17; Merchán, 1982, 57-58). Es necesario precisar, para no llevar a equívocos, que la fecha que mantenemos como de ocupación efectiva es la de 1173 , aunque en un reciente trabajo se ha publicado la fecha de 1167 , pero sólo debido a un error de transcripción (Matesanz, 1992, 53 y 55).

Comienza una época de engrandecimiento del monasterio, que experimentará un gran impulso económico y, por lo tanto constructivo. Se podría decir que, prácticamente, se edifica un monasterio nuevo siguiendo, en parte, la estructura de la planta del conjunto previo a 1173. Correspondiendo a la nueva fábrica premonstratense tenemos la mayor parte de la iglesia, a excepción de restos reutilizados de la fase previa, y la sala capitular y la capilla del Abad, que son de nueva planta. Por otro lado, coincidiendo básicamente con la planta de estructuras anteriores, aunque de nueva construcción, están el refectorio y la cilla. 
En definitiva, los ss. XII y XIII serán los de máxima expansión del monasterio, territorial, económica y espiritualmente. Posteriormente, se produce un estancamiento con un progresivo debilitamiento, a partir del s. XIV, cuando surgen numerosas rivalidades que llevaron a la abadía a continuos pleitos. A esto se une la falta de protección y de concesión de privilegios por parte de la monarquía, la exigencia de pago de impuestos para la guerra y la dificultad de obtener mano de obra. Lógicamente, el declive económico conllevó la decadencia moral en la comunidad religiosa. Sin embargo, todo esto no fue obstáculo para el mantenimiento, con altibajos, del monasterio (González de Fauve, 1992,81 y 313$)$.

Otra etapa de expansión y fortalecimiento económico se produce en los ss. XVII y XVIII, momento en que se realizan grandes reformas y ampliaciones; algunas de ellas inacabadas, como una que se comenzó por el sur y que habría eliminado las fachadas medievales de cocina y refectorio.

El monasterio se ve afectado por el proceso desamortizador del s. XIX y en 1835 se produce el primer abandono, pero será ya en 1837 cuando se desaloje definitivamente produciéndose la paulatina ruina con el consabido deterioro de sus fabricas y pertenencias. El abandono en el que quedó sumido desde entonces trajo una serie de consecuencias:

a) Ruina: El monasterio comenzó a sentir la falta de conservación periódica, el deplorable estado del edificio es patente en documentos gráficos de la época (Fig. 2a), en los cuales se puede observar cómo los tejados y algunas cubiertas están derruidas. Este estado es también constatable posteriormente en la fotografía aérea de 1956 (vuelo americano).

b) Expolio controlado: A finales del s. XIX (1871) se desmontó parte de los capiteles más representativos (Fig. 3) (según los criterios de la época) y fueron trasladados al Museo Arqueológico Nacional (Bravo y Matesanz, 1986, 19). Aunque no vamos a entrar en disquisiciones, hay un hecho claro: no es aconsejable descontextualizar ciertos elementos y menos de manera tan poco afortunada como en este caso, pero también debemos decir que, viendo el proceso de ruina implacable que siguió, hay que pensar que posiblemente ese grupo de capiteles se salvó de su desaparición, destrucción o rotura.

c) Expolio incontrolado: La rapiña ha provocado la desaparición de múltiples capiteles, otros elementos decorativos, sarcófagos y gran cantidad de elementos pertenecientes a la propia fábrica (Fig. 4). Este hecho más la falta de sensibilidad de las autoridades competentes ante este gravísimo problema, hicieron el resto para la total ruina del conjunto. 

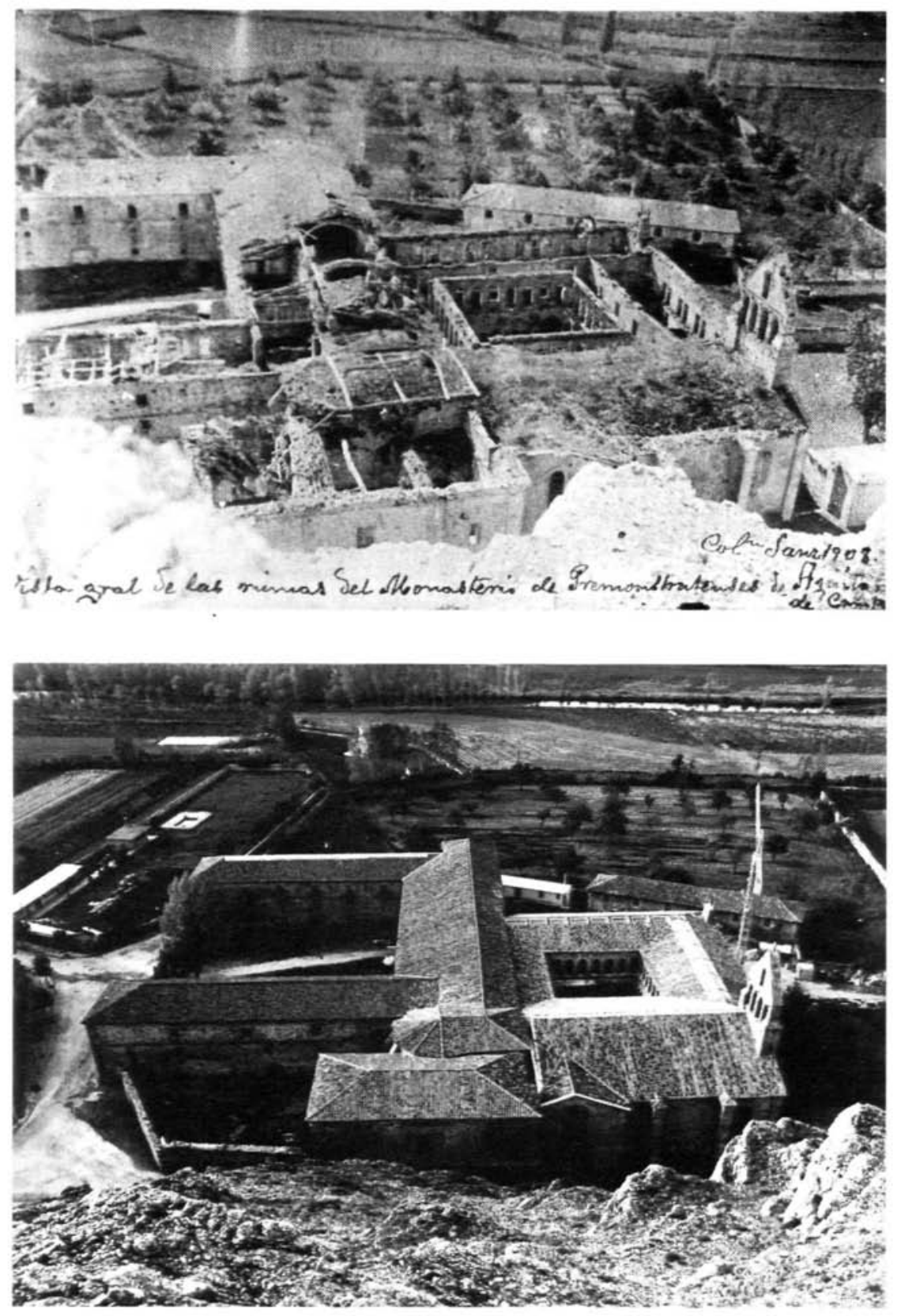

Figura 2. a) Aspecto ruinoso del monasterio en 1908. Foto: Col. Sanz. b) El monasterio en 1984. Foto: J. L. Alonso 


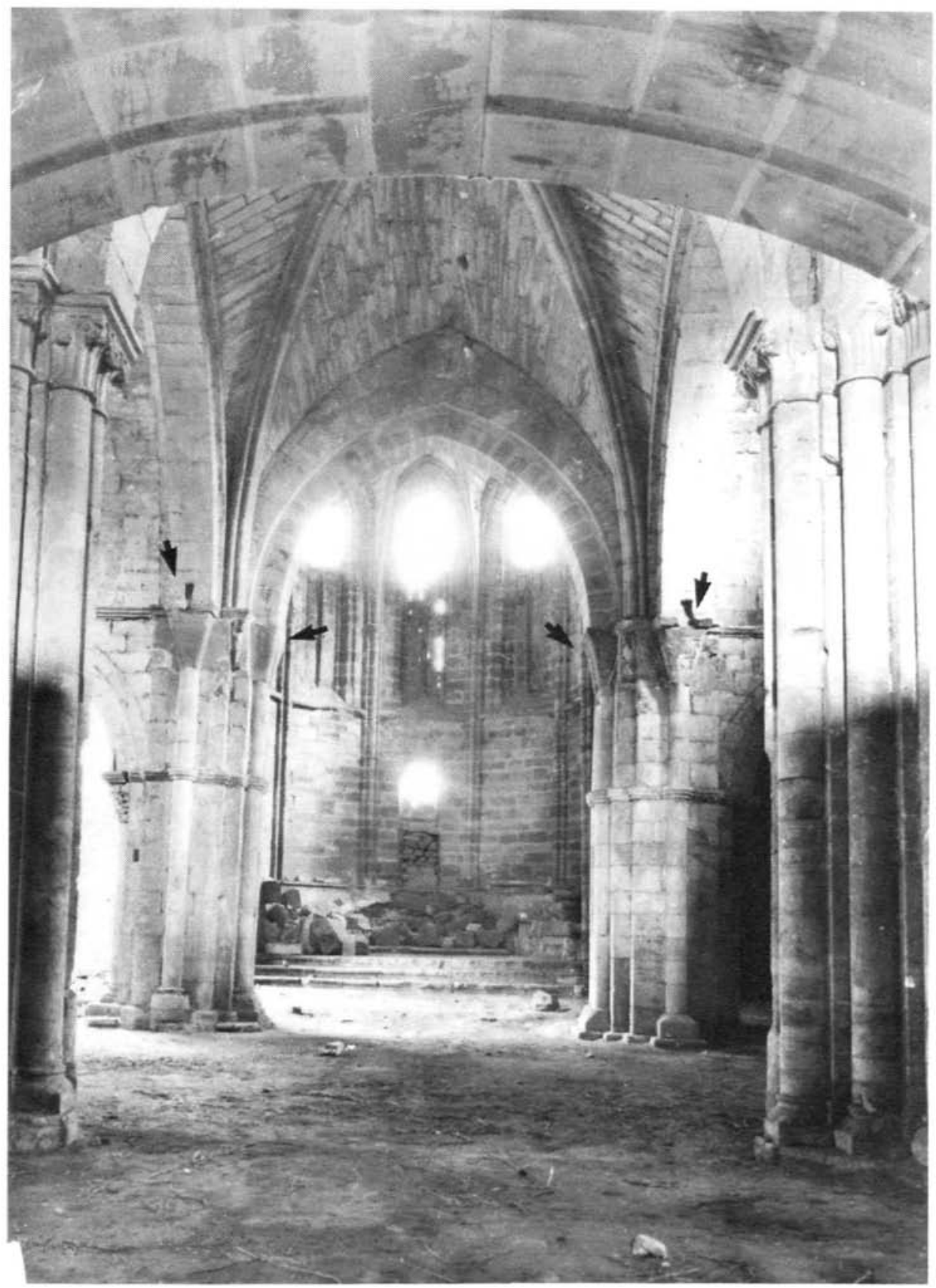

Figura 3. Vista general de la iglesia desde el oeste. Las flechas indican los capiteles que fueron desmontados. Foto: Archivo Mas 


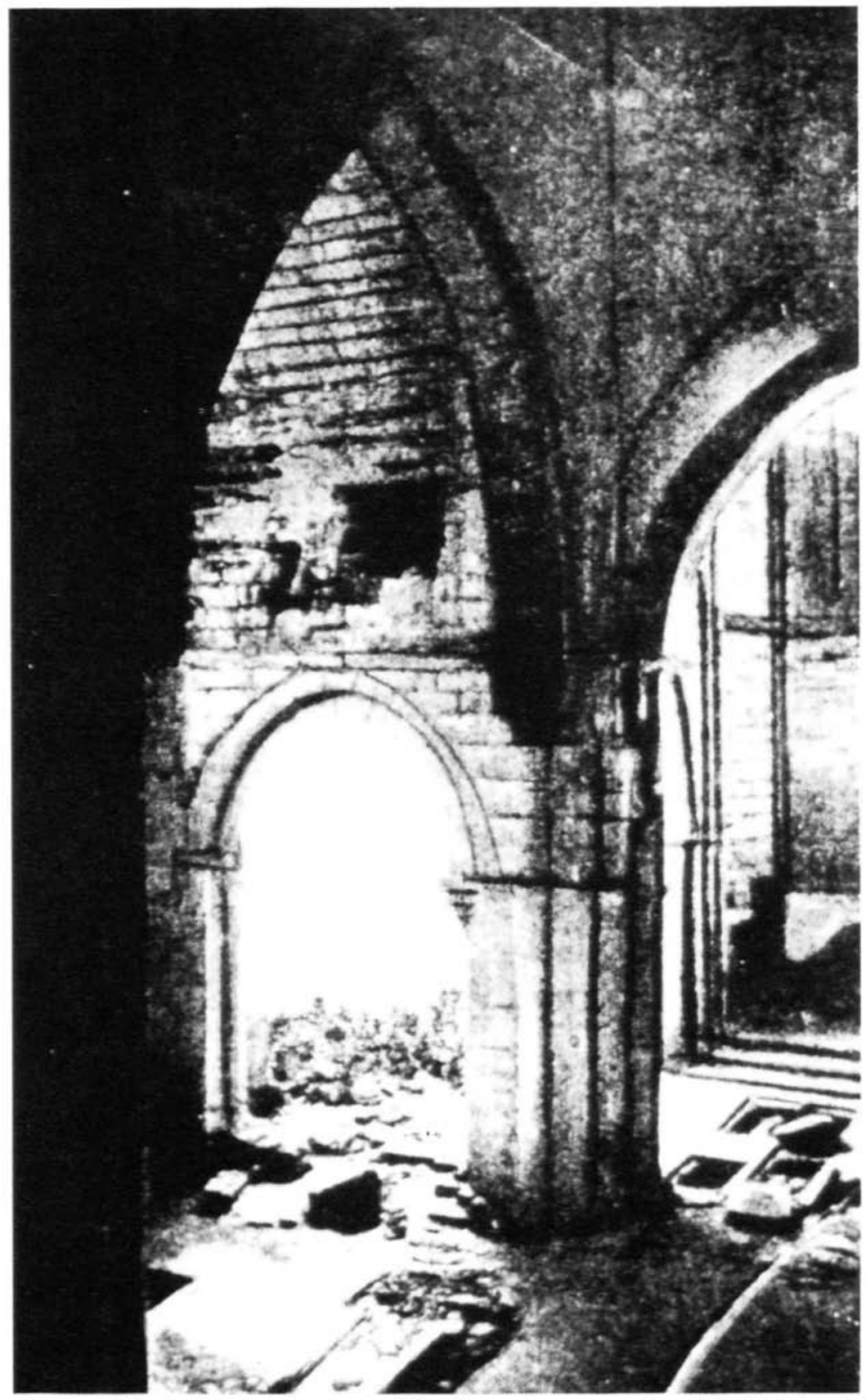

Figura 4. Vista del pilar norte del arco triunfal y el arco de acceso a la capilla del Cristo (años 30). Foto: Espasa Calpe 


\section{INTERVENCIONES RESTAURADORAS}

La primera intervención, muy puntual, parece que se documenta durante los años de la Segunda República (1931-1939) y consiste en la actuación en el tejado de la iglesia.

La segunda es considerada como la primera en la que hay cierta continuidad y se llevará a cabo entre 1955 y 1968, siendo arquitecto director A. Arenillas. Las zonas en las que se actúa son: tejados en la Capilla del Cristo, zona de dormitorios al este con su continuación hacia el sur en la ampliación del s. XVIII y alas norte y sur de la mencionada ampliación.

El problema fundamental de esta intervención fue su dureza, aunque tuvo aspectos útiles y positivos que pararon en parte el deterioro del conjunto, como las ya referidas reparaciones de tejados en amplias zonas del monasterio. Sin embargo, realizó actuaciones puntuales realmente desafortunadas, como fue el desmontaje del coro situado a los pies de la iglesia, lo que supuso la pérdida de este elemento que desapareció por completo (Fig. 5). También la intervención en el claustro alto fue bastante desatinada. Comenzó a desmontar la referida segunda planta cuando se encontraba completa y en buen estado ( $\sin$ cubierta ni techumbre, pero completa) (Fig. 6a). Su intervención consistió en desmontar el ala este y luego recomponerla, pero sin seguir el esquema previo. La planta alta la reconstruyó apoyándola en la iglesia por el norte y en el refectorio por el sur, con pretensiones de desmontar el resto del claustro alto, intentando, probablemente, imitar la configuración de un monasterio cisterciense prototípico (esto es una suposición, pues no hay otra explicación lógica para tamaño desatino, que destruyó gran parte de la estructura preexistente del claustro que, aunque en ruinas, estaba prácticamente completo).

En el proceso de montaje cambió la estructura original en cuanto a la forma de los arcos, convirtiendo arcos de medio punto en apuntados o ligeramente apuntados con concepciones puristas absolutamente equivocadas. Los contrafuertes fueron convertidos en pilastras que intentaban homogeneizarse con la planta alta del s. XVII. Un nuevo error fue la introducción, de manera indiscriminada, de piedra arenisca de color rojizo que no tiene nada que ver con el resto de la fabrica del monasterio. Los capiteles originales fueron desmontados y sustituidos por burdas copias "pseudorrománicas" y los fustes de piedra arenisca reemplazados por otros de $u$ ralita (Fig. 6b).

En el interior de la iglesia fue desmontado un coro (ya referido anteriormente), ubicado en los dos últimos tramos hacia el oeste, ocupando las naves central y lateral sur (Fig 5), y que podríamos situar cronológicamente en el s. XVI.

Dato interesante y con repercusiones claramente negativas desde el punto de vista arqueológico, es la remodelación del suelo de la iglesia, en la cual se sustituyeron en su totalidad las cubiertas de piedra (enlosado) de los enterramientos por una capa de doble rasilla y hormigón. 


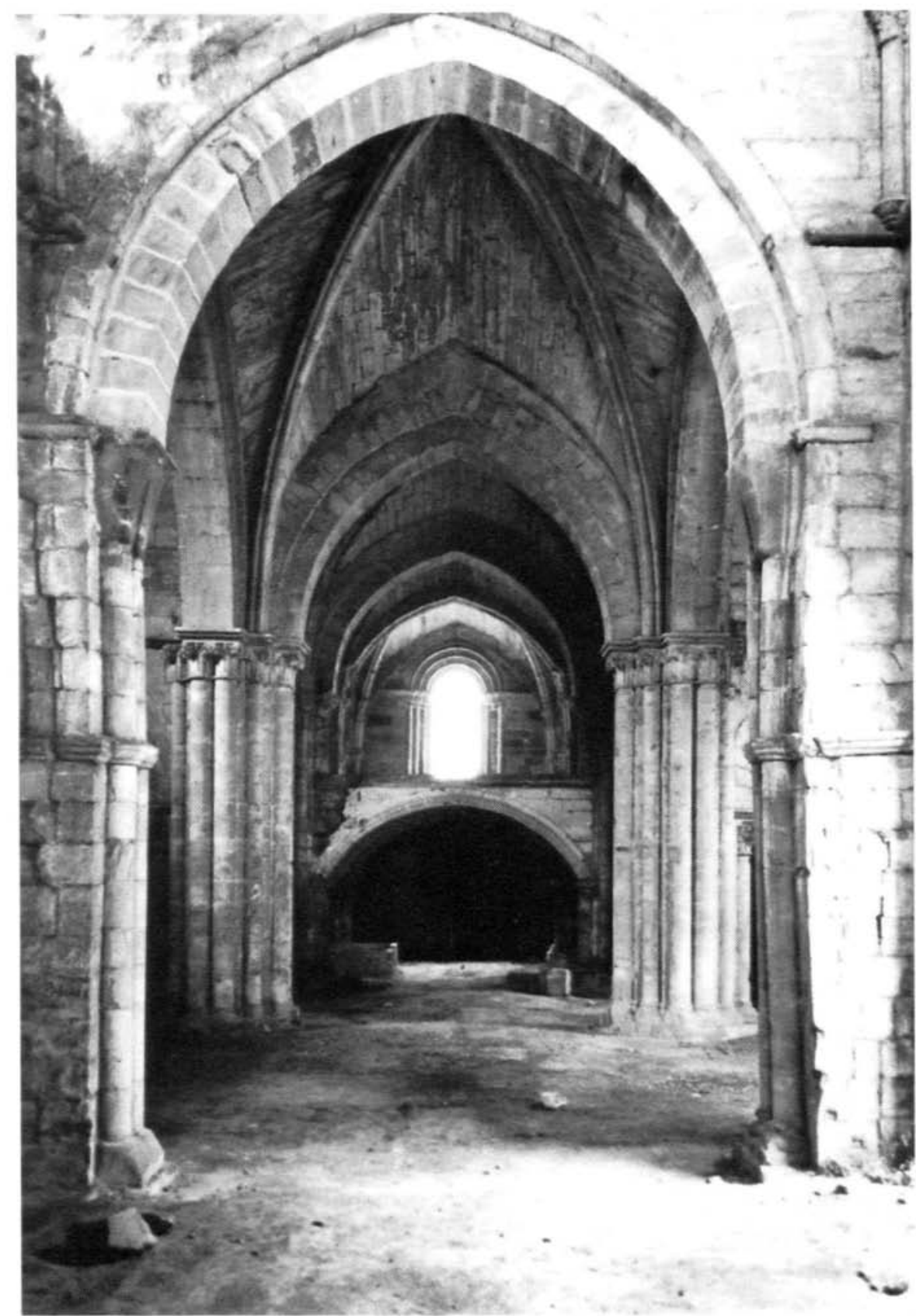

Figura 5. Vista general de la iglesia desde el este. Al fondo puede verse el coro desaparecido. Foto: Archivo Mas 

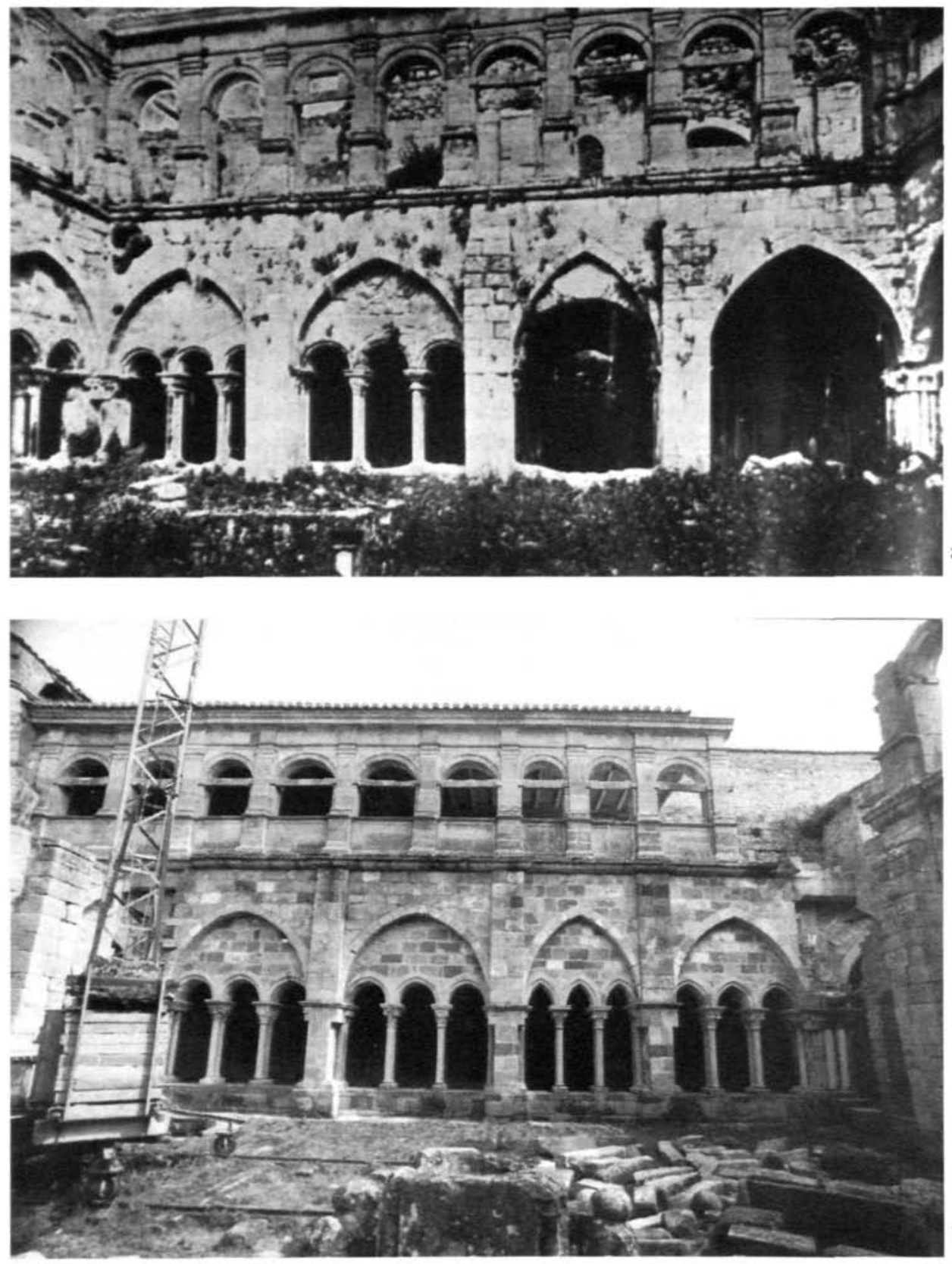

b)

Figura 6. a) Aspecto de la fachada este del calustro en 1900. b) Aspecto de la fachada este del claustro tras la intervención de A. Arenillas (1978). Foto: L. Caballero 
En el ábside central gótico se desmontaron los tres peldaños que daban acceso al mismo, para poner a la luz las pequeñas basas de los pilarcillos del mismo. Tras desmontar los escalones, homogeneizando el suelo a la misma altura, lo remató colocando en todo el espacio del ábside una plancha de hormigón. En la zona del presbiterio elevó el nivel colocando dos escalones que ocultaban las basas de las columnas del arco triunfal, por lo cual desmontó el suelo y volvió a montar unas reproducciones de las mismas, elevándolas sobre el nivel previo.

En otras zonas de la iglesia sencillamente colocó planchas de hormigón y después imitó la compartimentación de los enterramientos. Lo curioso de todo ello es que para realizar todas estas reformas tuvo que ver ciertos elementos originales que habrían supuesto una intervención más correcta y sin necesidad de interpretaciones dificultosas $a$ posteriori. Después de cambios tan drásticos en la restauración, en la intervención arqueológica se ha tenido que hacer arqueología de los años de la actuación de Arenillas. Sería interesante, al respecto, que también a los arquitectos se les exigiese una memoria en la que explicasen puntualmente el resultado de sus intervenciones.

Todos sabemos que una cosa es el proyecto y otra la realidad. El arquitecto a la hora de intervenir puede ser tan destructivo como el arqueólogo (Latorre, 1987, 194) que no documenta ni interpreta científicamente lo que excava, pero con la diferencia que en arqueología, por definición, por técnica y por necesidad, se documenta el antes y el después y por lo tanto esa destrucción queda perfectamente registrada (Caballero, 1987, 23-24).

De todas formas la intervención de Arenillas se realiza en un momento en el que pensar en ciertos conceptos era imposible. En estos momentos conceptos tales como la documentación básica previa, en donde se incluye la intervención arqueológica (asesorada, desde el punto de vista técnico, por el arquitecto), equipo interdisciplinar, etc., están bastante extendidos en la teoría (Latorre, 1987, 194; Caballero, 1987, 39-41), pero apenas son puestos en práctica. Todavía, a veces, se ve al arqueólogo no como la persona responsable de dar un uso y valor científicos a los restos y que aporta datos importantes para el conocimiento del edificio y consiguientemente necesarios para facilitar la elaboración del proyecto de restauración, sino como un elemento intruso distorsionador y retardante del proyecto arquitectónico (Saenz de Oiza, 1983, 136).

Si Arenillas es criticable en cuanto a las transformaciones indiscriminadas sin rigor, también hay que aprobar las actuaciones que supusieron un beneficio para el conjunto monástico, como fueron el techado de toda la ampliación barroca, así como de la capilla del Cristo.

A partir de esta intervención, que cabría pensar se trataba de una restauración si no definitiva si que pudiese impedir el progresivo deterioro sufrido por el edificio hasta entonces, lo que ocurre es la paralización de los trabajos y un nuevo abandono. Con el cual vuelven a aparecer la ruina y el expolio.

Con anterioridad a la tercera intervención (desde 1978) se realiza un desescombro previo que es beneficioso en tanto en cuanto es uno de los motores para la puesta en 
marcha de las obras de restauración del edificio. No obstante, al ser un desescombro incontrolado desde el punto de vista arqueológico, multitud de datos importantes para la historia arquitectónica y artística del edificio y numerosos materiales se perdieron.

Hay que esperar al año 1978 para que se acometa la tercera intervención. Se trata de la segunda restauración, más dilatada en el tiempo que la realizada por A. Arenillas (al parecer aún no han concluido los trabajos), llevada a cabo por José M. ${ }^{a}$ Pérez (Fig. 2b). Esta actuación restauradora se acomete con otra filosofía, más seria y rigurosa que la anterior. Se mantuvieron criterios correctos en el tratamiento de ciertos paramentos y en el de los capiteles del claustro, sin embargo en lo que se refiere a la relación con la arqueología hay que constatar que, en general, el desinterés y, en ciertos momentos, el obstruccionismo han sido palpables. Las repercusiones en la arqueología de esta tercera acción restauradora en general han sido negativas: en las fases de pavimentación de refectorio, cocina, cilla, capilla del Cristo, zona de entrada previa a la capilla del Cristo e iglesia, jamás ha habido supervisión por parte de la dirección de las excavaciones arqueológicas (1978-1991). En todas esas zonas quedaron áreas en reserva (sin excavar) que, a posteriori, nos informaron, fueron removidas sin control arqueológico alguno. La cantidad ingente de zanjas realizadas en el monasterio, para diferentes fines como las acometidas de agua y luz, tampoco han sido supervisadas. En diversas zonas en que, casualmente, se ha podido excavar con posterioridad a la realización de zanjas, se ha constatado el destrozo que las mismas produjeron. En zonas limítrofes a las dependencias centrales del monasterio (adquiridas por el Centro de Estudios del Románico), al oeste de la cilla, se realizaron zanjas sin control.

Paralelamente al proceso de restauración se inician las excavaciones arqueológicas. Las distintas campanas se han centrado en cocina, refectorio, cilla, corredor sur del claustro, iglesia, capilla del Abad, entrada y patio de acceso del monasterio (Fig. 7).

En definitiva, ha sido una situación a todas luces anti-arqueológica por mucho que el arquitecto director se encargase de difundir el apoyo — teórico- a la arqueología.

\section{REPERCUSIÓN DE LAS RESTAURACIONES EN LA INTERVENCIÓN ARQUEOLÓGICA}

Al margen de todas las intervenciones restauradoras, reparadoras y remodeladoras previas a las intervenciones llevadas a cabo en este siglo, hay que recordar que el monasterio de Santa María la Real es un paradigma de la perduración en el tiempo de una comunidad monástica. El gran número de remodelaciones que se suceden desde el s. VII hace que haya una gran complejidad y a veces falta de claridad en los niveles arqueológicos; siendo un conjunto con un gran potencial científico.

Partiendo de esa base, para el arqueólogo los propios recursos arqueológicos del subsuelo son insuficientes, necesitando, además, la información que la propia arquitectura del edificio proporciona (Caballero, 1987, 33-34). Esto implica que una intervención 


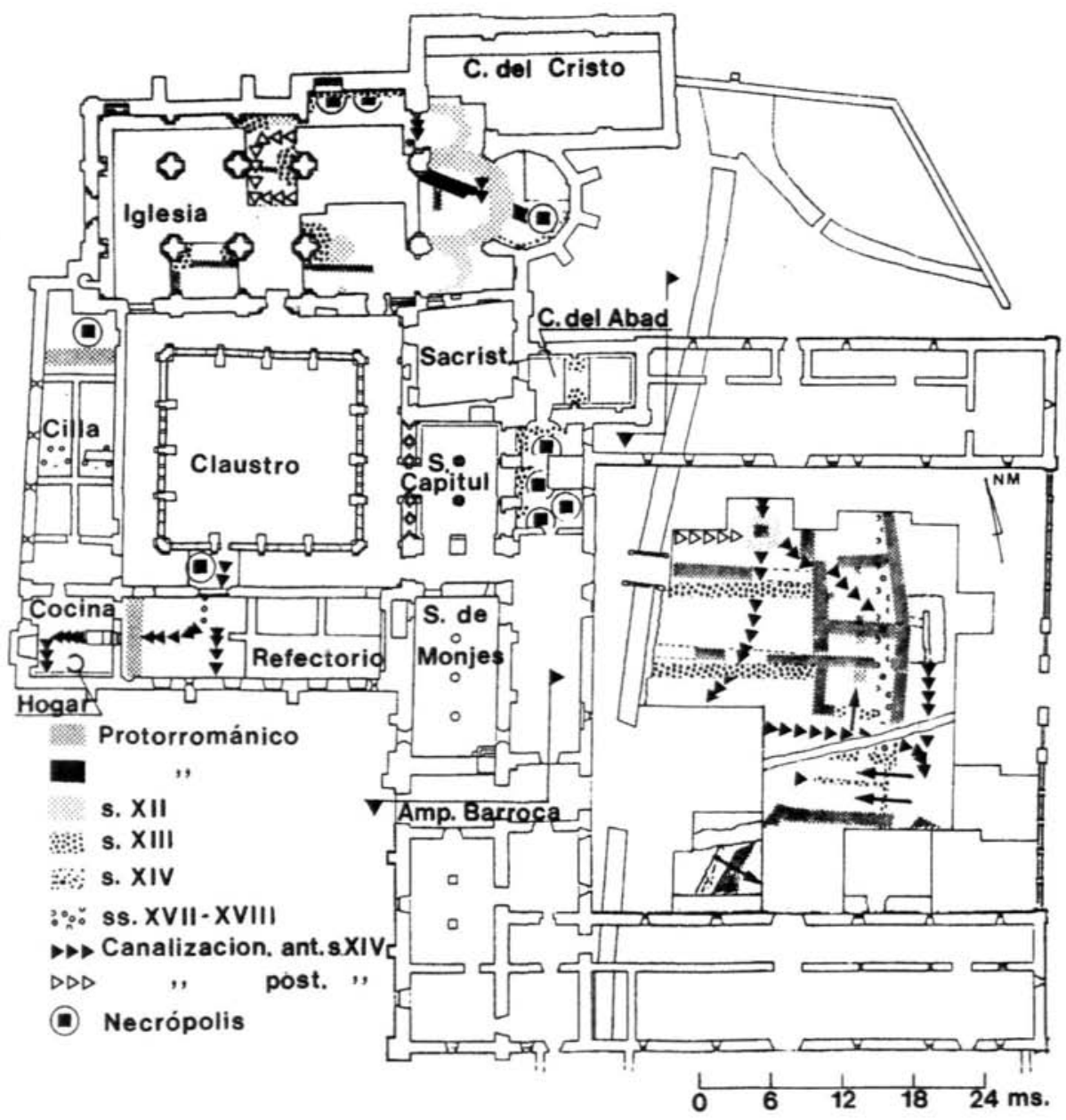

Figura 7. Plano general esquemático del monasterio con las zonas de intervención arqueólogica

restauradora agresiva en el edificio puede destruir o transformar esa información fundamental para la arqueología y para la misma arquitectura. Es en este momento cuando el arqueólogo debe integrarse plenamente en el contexto arquitectónico del edificio, por mucho que Saenz de Oiza $(1987,136)$ reclame solamente para los arquitectos la intervención en los edificios históricos. Se trataría de una integración desde un punto de vista elemental, sin entrar en conceptos básicos en cuanto al equipo que debe intervenir y la 
investigación arquitectónica previa que debe aplicarse (Latorre, 1987, 194). Para el arqueólogo es fundamental el análisis de los paramentos existentes, la conjunción de sus muros, el tratamiento efectuado en su superficie, los elementos decorativos, etc., en definitiva cualquier dato que sirva para el esclarecimiento de la historia del edificio (Caballero, 1987, 26-27). La arqueología por sí sola, en un contexto como el de Santa María la Real, resultaría incompleta y parcial y lo mismo ocurriría con la arquitectura aislada. El trabajo ha de ser, pues, coordinado, nunca en detrimento de una de las partes, porque eso perjudicaría el estudio integral de un conjunto (Caballero, 1987, 39-41).

El expolio es otro de los aspectos que hay que tener muy en cuenta pues también influye negativamente por la pérdida de datos; datos que son necesarios para el estudio de un conjunto edificado como el que tratamos. En Santa M. ${ }^{a}$ la Real el expolio, como ya se ha comentado anteriormente, se ha producido a gran escala en sus dos formas posibles: controlado e incontrolado. Los capiteles que fueron desmontados a finales del s. XIX y trasladados al Museo Arqueólogico Nacional no fueron catalogados con precisión, de tal forma que no se determinó su ubicación exacta. Recientemente fue analizado el posible lugar que ocuparon en el monasterio para poder comprobar series o ciclos escultóricos (Bravo y Matesanz, 1986, 117-123; plano 1). Todos los datos anteriormente expuestos nos llevan a reiterar que es fundamental la documentación previa en todo edificio que vaya a sufrir una intervención restauradora de mayor o menor envergadura.

Estos inconvenientes provocan que la arqueología del subsuelo no deba usarse por sí sola para el estudio de la historia de este edificio, sino complementada con un estudio y análisis de los paramentos y estructuras conservados en el monasterio que ha llegado a nuestros días.

\section{EL CASO DE LA IGLESIA PREVIA A LA LLEGADA, EN 1173, DE LOS PREMONSTRATENSES}

Uno de los ejemplos que mejor ilustra la relación arqueología-arquitectura, en el caso que nos ocupa, es el referente al hallazgo, gracias a las excavaciones arqueológicas, de la estructura de la iglesia previa a la llegada de los premonstratenses al monasterio.

Hay que partir de la base que creemos que los premonstratenses llegan a un monasterio que en absoluto estaba en una situación crítica. Como ya señalamos en la primera parte de este trabajo, la documentación es bastante imprecisa a este respecto, pero hay numerosos datos indirectos que nos dan idea de la magnitud del monasterio antes de 1173. Ya apuntábamos en 1986 (Bravo y Matesanz, 154) que sobre el monasterio que ocuparán los premonstratenses poseían derechos los Laras y los Osorios (Merchán, 1982, 55), poderosas familias que desde luego tenían fuerza suficiente como para que nos haga pensar que se trataba de un conjunto de considerable importancia (Merchán, 1982, 55 y 56). De hecho el edificio aparecido es de unas características tales que así lo indican. Es de planta basilical con tres naves y tres ábsides semicirculares, contrafuertes en los mis- 


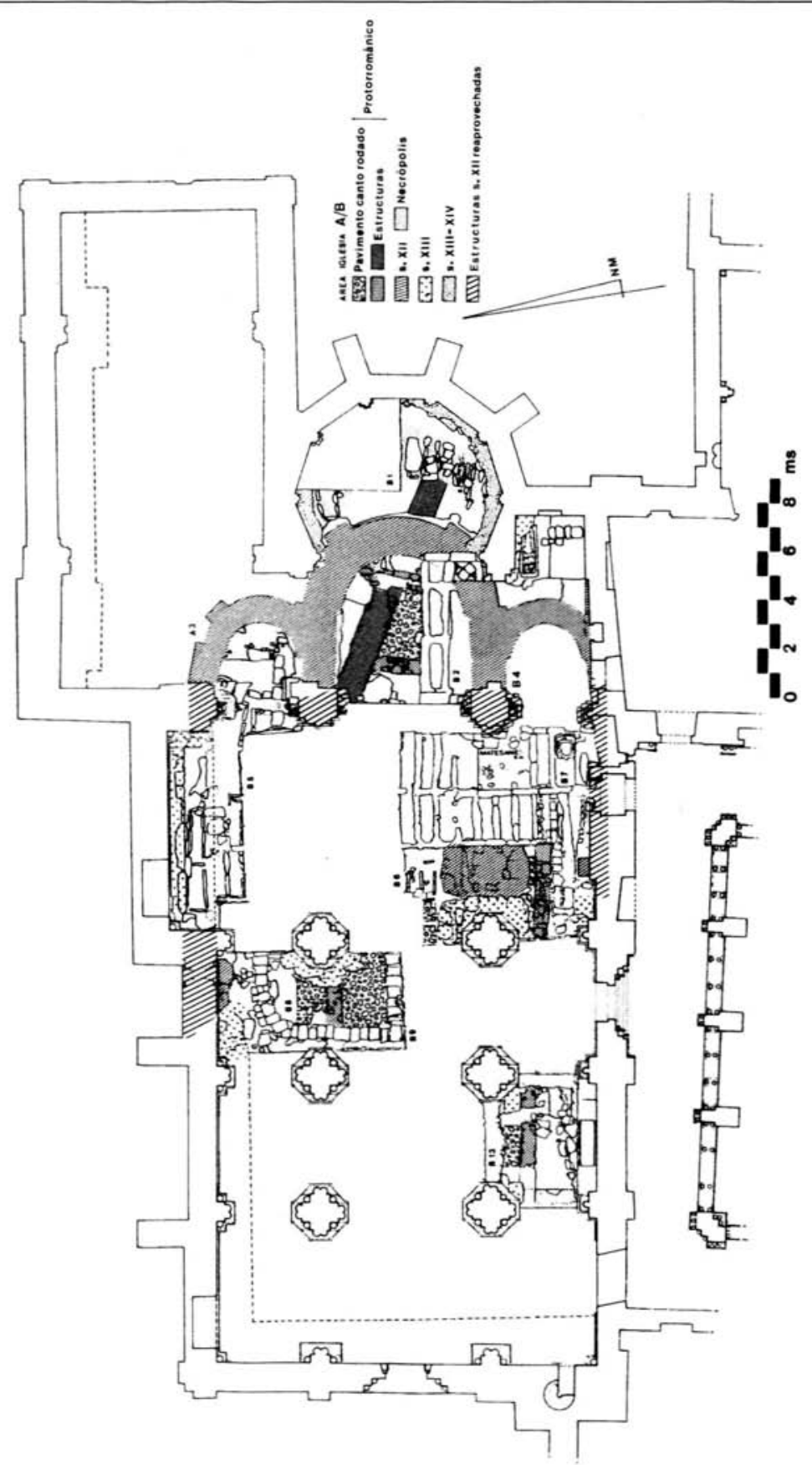



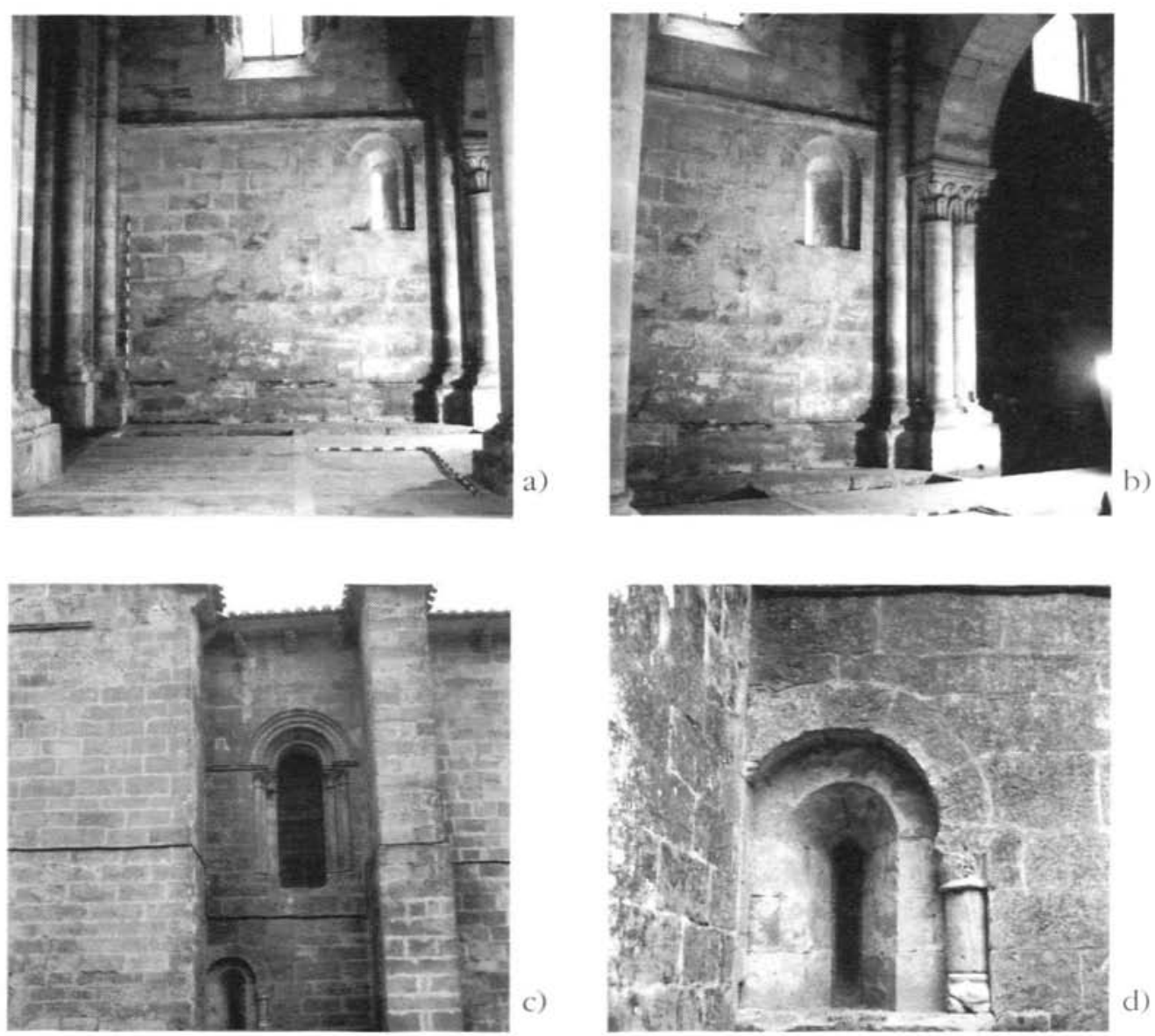

C)

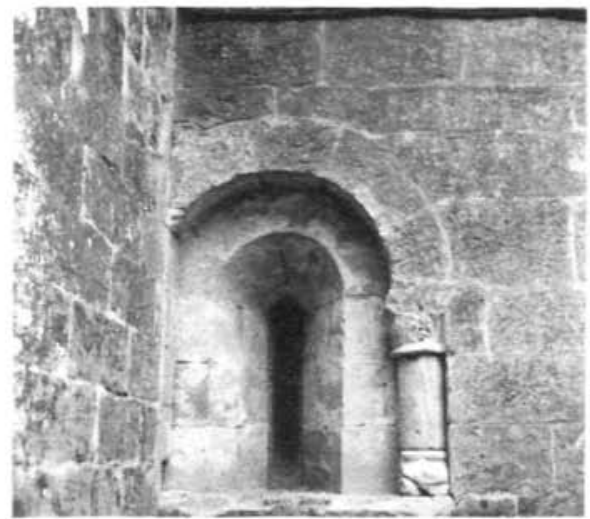

d)

Figura 9. a) Paramento norte en zona B-8 (interior), Vista del muro románico con la ventana abocinada a la derecha. b) Detalle del paramento anterior desde el suroeste. c) Paramento norte correspondiente a la zona B-8 al exterior. d) Detalle de la ventana románica al exterior. Fotos: P. Matesanz

mos y también en la conexión entre ábsides; con nave de crucero sin brazos sobresalientes. Los elementos sustentantes son pilares cruciformes, con una distancia entre los mismos diferente a la de la iglesia actual ( $1 .^{a}$ iglesia premonstratense). No obstante, se desconoce, por el momento (dado que hay zonas no excavadas), el límite de la iglesia por el oeste, aunque parece existir una ruptura que nos indica que no quedaría más iglesia que la se ha documentado, tanto arqueológica como arquitectónicamente.

La intervención arqueológica en la iglesia se inicia en 1983 cuando nos enteramos que el arquitecto pretendía hacer una zanja de drenaje perimetral en paralelo al muro 
norte de la misma y de la capilla del Cristo. Se llegó a un acuerdo para que esta intervención la llevásemos a cabo nosotros, los arqueólogos. El resultado de esta primera actuación en la iglesia fue la localización de parte del ábside norte. A partir de este momento es cuando se plantea una intervención más sistemática en extensión en la iglesia.

Uno de los problemas más destacables ha sido la eliminación de las capas de hormigón que cubrían los enterramientos y algunas otras zonas, donde el espesor llegaba a los $15 \mathrm{cms}$ (estas capas proceden de la intervención de A. Arenillas). Hubo que utilizar martillo neumático y supuso mucho esfuerzo.

Para una mejor comprensión se plantea explicar la iglesia de oeste a este y de norte a sur, comenzando desde el tramo B-8 (siendo la zona excavada más al oeste junto al paramento norte) (Fig. 8), en donde localizamos la zona de rotura de la iglesia románica y el comienzo de la continuación de la primera premonstratense. En esta zona, en el paramento interior, hay una ventana abocinada situada muy próxima al pilar izquierdo de la que teníamos sospechas en cuanto a su pertenencia a la iglesia previa ya detectada por Lampérez (1930, 408). Su proximidad al mencionado pilar, el arco cortado por una imposta decorada y el hecho de que sus características formales que difiriesen de las ventanas representadas en el monasterio, así nos lo confirmaban (Fig. 9a y b). Añadidas a los datos anteriores, las excavaciones arqueológicas acabaron por ratificar las sospechas existentes a ese respecto.

Se identificaron dos tipos diferentes de cimentación: una con grandes bloques de piedra calcárea con una amplia superficie de apoyo y argamasa y otra con mucha piedra de pequeño y mediano tamaño y gran cantidad de argamasa. La primera corresponde a las estructuras de la primera iglesia premonstratense y la segunda a la románica, previa a la anterior. Los distintos tipos de cimentación se adaptaban perfectamente a las respectivas zonas que considerábamos con cronologías diferentes, lo cual fue bastante clarificador.

El análisis del paramento norte hacia el oeste nos indica que no hay referencias que nos hagan pensar en su continuidad hacia ese lado. Así pues, si tanto en el estudio de paramentos como en el del subsuelo no encontramos más referencias, tenemos que pensar que el límite oeste de la iglesia románica se localiza ahí. Obviamente ello no implica que la iglesia románica en origen acabara en ese punto, tan sólo nos dice que las referencias a la misma se pierden en ese lugar. Sin embargo, el paramento norte hacia el este todavía planteaba problemas, como por ejemplo, dilucidar si ese entrante extraño que se puede observar en la nave de crucero, correspondería a un posible tramo del transepto (Fig. 8). Datos curiosos en referencia a esa cuestión eran que, justo en esa zona, el ancho entre pilares se ampliaba considerablemente y que, concretamente ahí, se perdían las referencias a las irregularidades observadas en los pilares, además del comienzo de pilares cruciformes sobre una base octogonal con dobles columnas adosadas en los frentes y sencillas en las esquinas. 


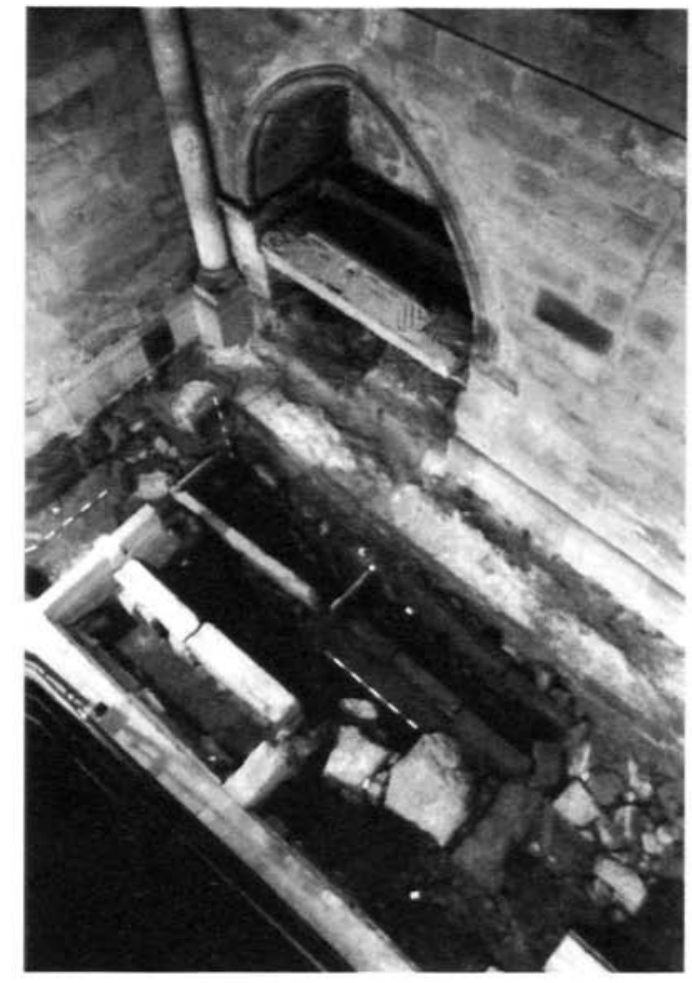

a)

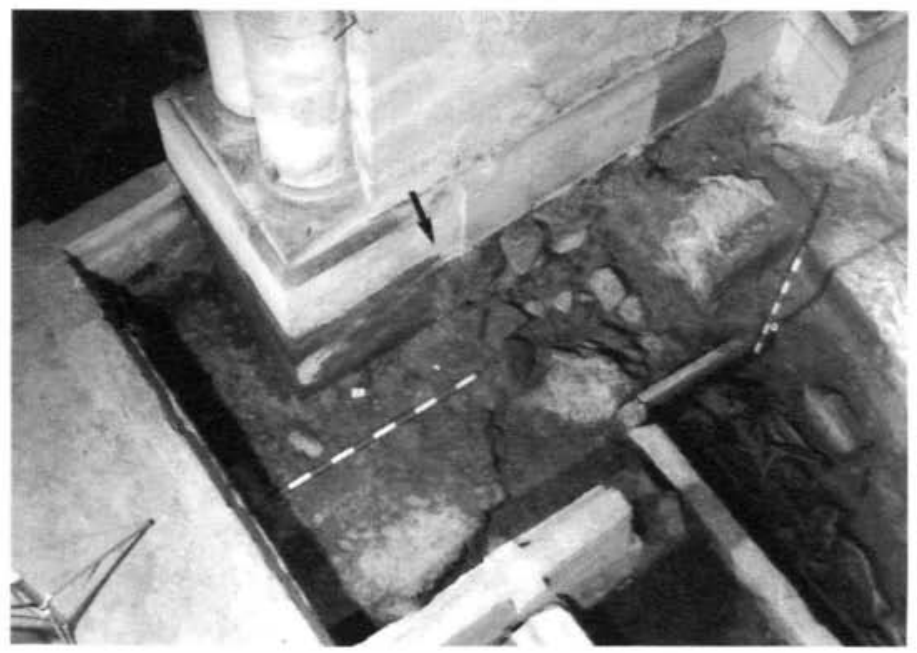

b)

Figura 10. a) Vista de la zona B-5 desde el sureste. b) Detalle de la esquina noroeste de la zona B-5, en donde se observa el arranque del sillar del muro románico (con una flecha). Fotos: P. Matesanz 


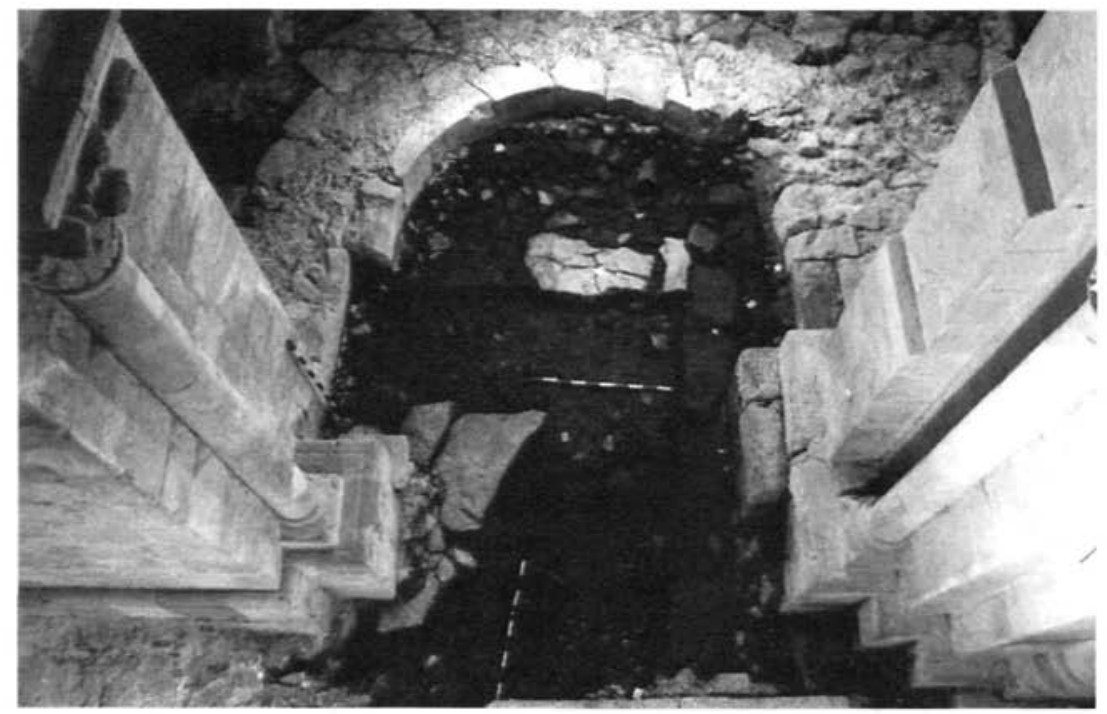

a)

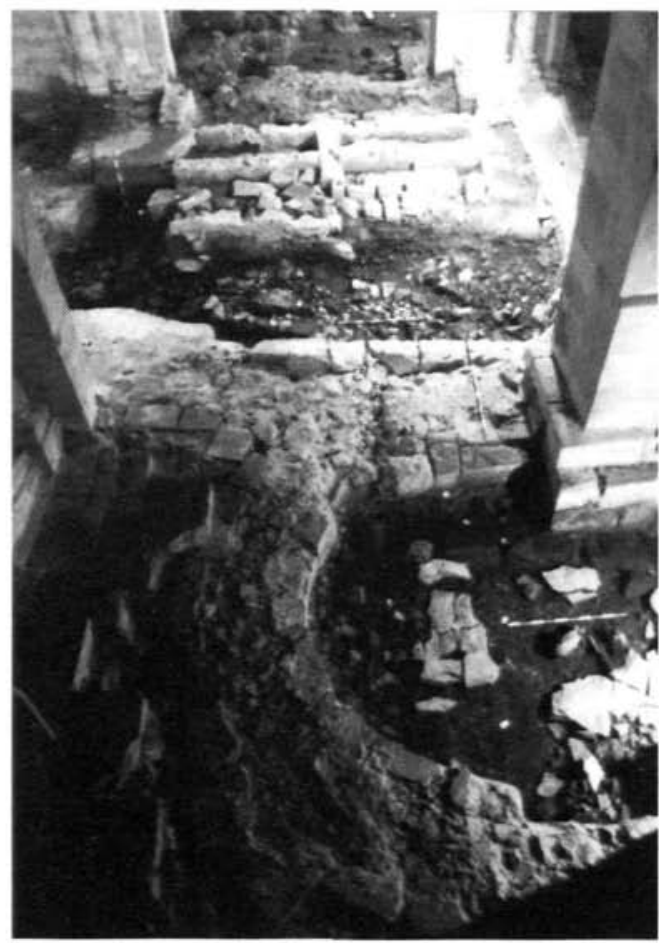

b)

Figura 11. a) Vista del ábside lateral norte. b) Vista desde el norte de los ábsides de la cabecera románica. En primer término el ábside lateral norte en su conexiôn con el pilar norte del arco triunfal. Fotos: P. Matesanz 
Volviendo al tramo de paramento norte en B-8, se observa que la pilastra se adosa y rompe en parte al mismo, especialmente al zócalo o faja resaltada en la zona inferior de la pared, rematada en su parte superior por una pieza moldurada (de bocel con dos líneas incisas), que, por cierto, no aparece en ninguna otra parte del edificio, a excepción de la que se localiza en el paramento sur perteneciente también a la iglesia románica. Observábamos también que después de esta pilastra había una brusca interrupción sin solución de continuidad. La interpretación de esta cuestión se vio agravada, además, por la existencia de unas piezas molduradas (colocadas durante la intervención de Arenillas) en piedra arenisca de color claro que nos impedían comprobar como continuaba el paramento en esa zona (Fig. 10a) (zona B-5, esquina noroeste, Fig. 8). Al desmontar un añadido en la zona baja de la pilastra pudimos comprobar que, en línea con el muro románico de B-8, sobresalía un sillar que se ponía perfectamente en relación con el mismo (Fig. 10b). A todo ello había que añadir que en el exterior se podían constatar diversos detalles que se observaban en el interior con respecto al paramento románico: la ventana con arco de medio punto, al exterior, estaba parcialmente oculta por parte del muro premonstratense (Fig. 9c y d); esto nos indicaba que, con toda seguridad, el paramento románico continuaría hacia el este sin inflexiones (hacia esta posibilidad también apunta el sillar, a que antes hacíamos referencia, que sobresalía junto a la pilastra).

La existencia en el interior, en la zona B-5, de bloques de piedra caliza aislados nos hace pensar que pueden corresponder a los restos de la cimentación del muro románico o bien a una cimentación antigua reutilizada en época románica, pues su estructura podría considerarse arcaica (Fig. 10a).

En el extremo este de la zona B-5 se reproducía en parte la situación del lado opuesto: colocación de piezas postizas en el zócalo (Arenillas) y diferencia de cimentación en esa zona entre la de las estructuras premonstratenses y la del pilar románico adosado al este. En general, es una zona ésta muy trasformada por la intervención de Arenillas: colocación de un capitel falso de diferente módulo al original, sustitución de mucha sillería y abujardado generalizado con un rejuntado muy burdo.

A continuación del pilar, hacia el este, esa zona se ampliaba debido a la formación del espacio del transepto de la primera iglesia premonstratense y, posteriormente, por la construcción de la capilla del Cristo. La falta de indicios en paramentos se suplió con el descubrimiento del ábside románico lateral norte (Fig. 8 y Fig. 11a) que encajaba perfectamente con el pilar antes citado y con uno de los pilares del arco triunfal de la iglesia románica, concretamente el norte (trasformado por la construcción de la $1 .^{a}$ iglesia premonstratense, al tener que adaptar el pilar a los empujes de las nuevas bóvedas) (Fig. 11b).

La excavación arqueológica también puso a la luz el ábside central románico que encajaba con los pilares norte y sur del arco triunfal (Fig. 12a). Con respecto a los pilares del arco triunfal hay que decir que sufrieron los rigores de su transformación con la restauración de Arenillas, alterando las basas de tal forma que, al recrecer el nivel previo con la colocación de un escalón falso, tuvo que acortar los fustes de las dobles columnas adosadas realizando unas basas falsas (Fig. 12 b). Lo curioso del tema es que Arenillas 

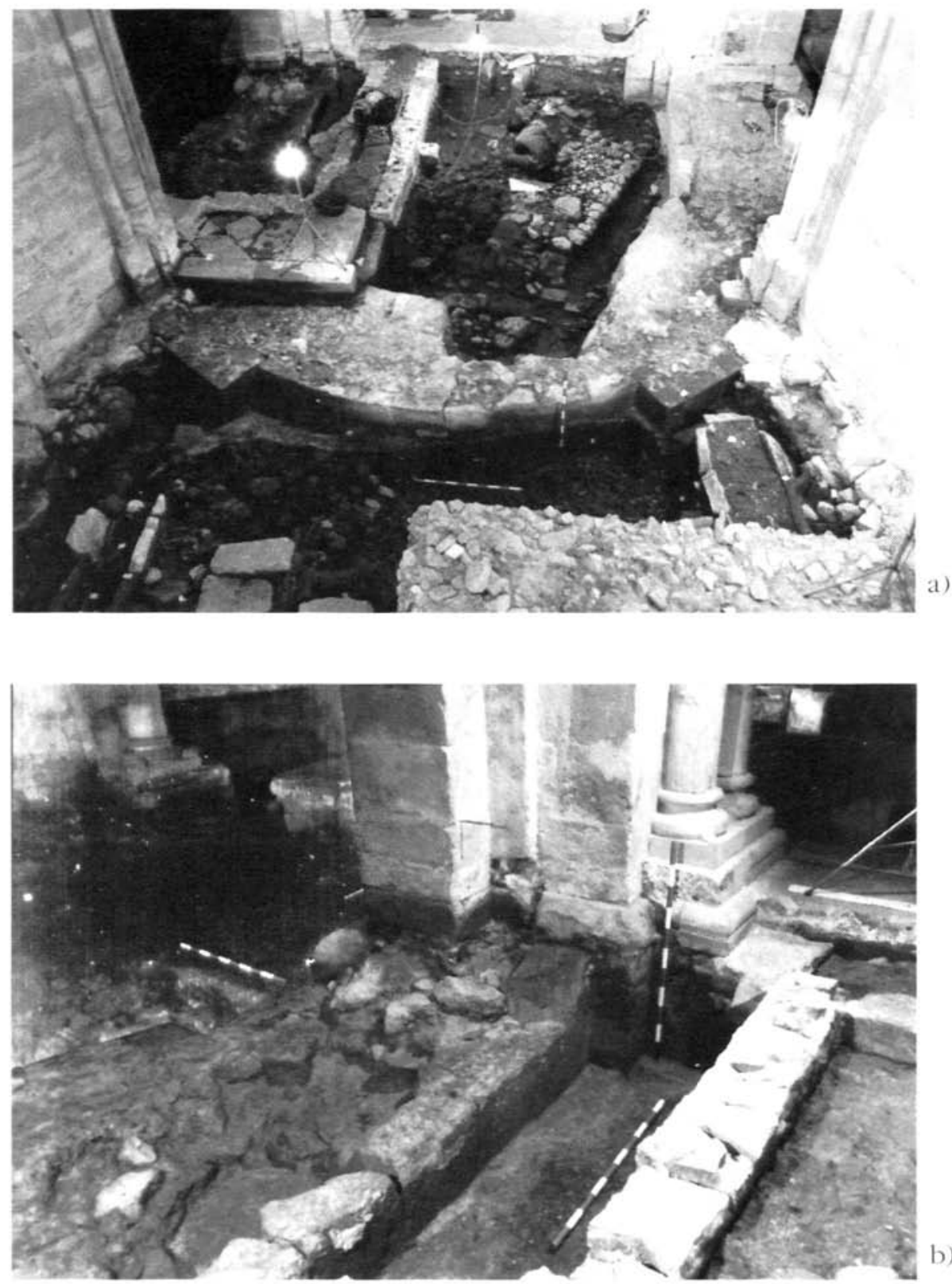

Figura 12. a) Vista general del áhside central románico desde el este. b) Detalle del pilar sur del arco triunfal en su conexión con el ábside central y lateral sur. Fotos: P. Matesanz. 


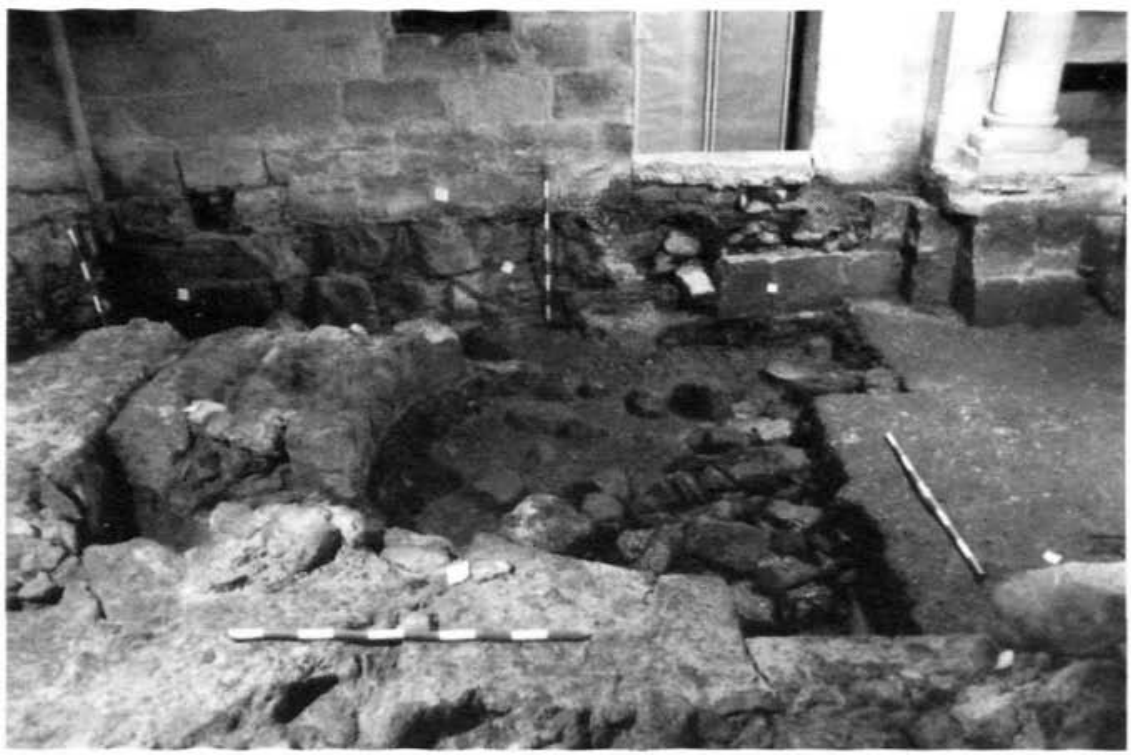

a)

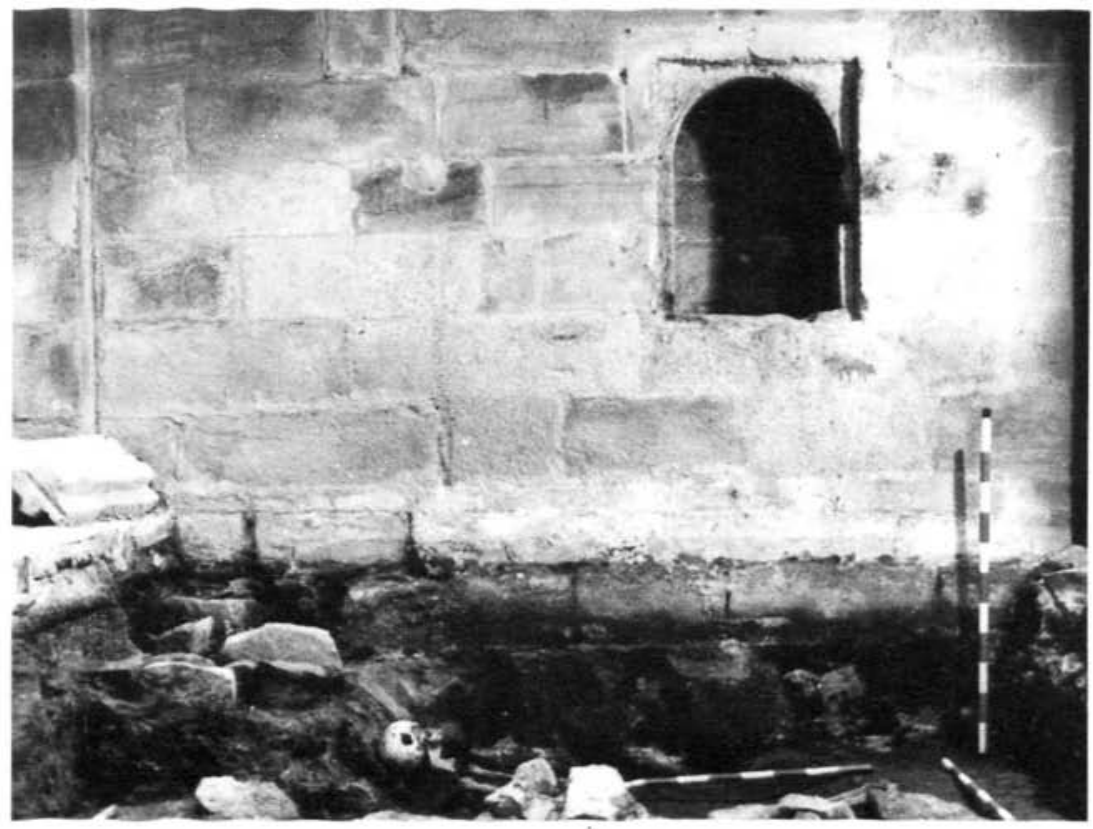

b)

Figura 13a. Vista del muro sur en la zona B-4. Superposición de los niveles premonstratenses sobre los románicos. b. Detalle de la anterior, en donde puede verse el abujardado generalizado que impide analizar con claridad los paramentos. Fotos: P. Matesanz 


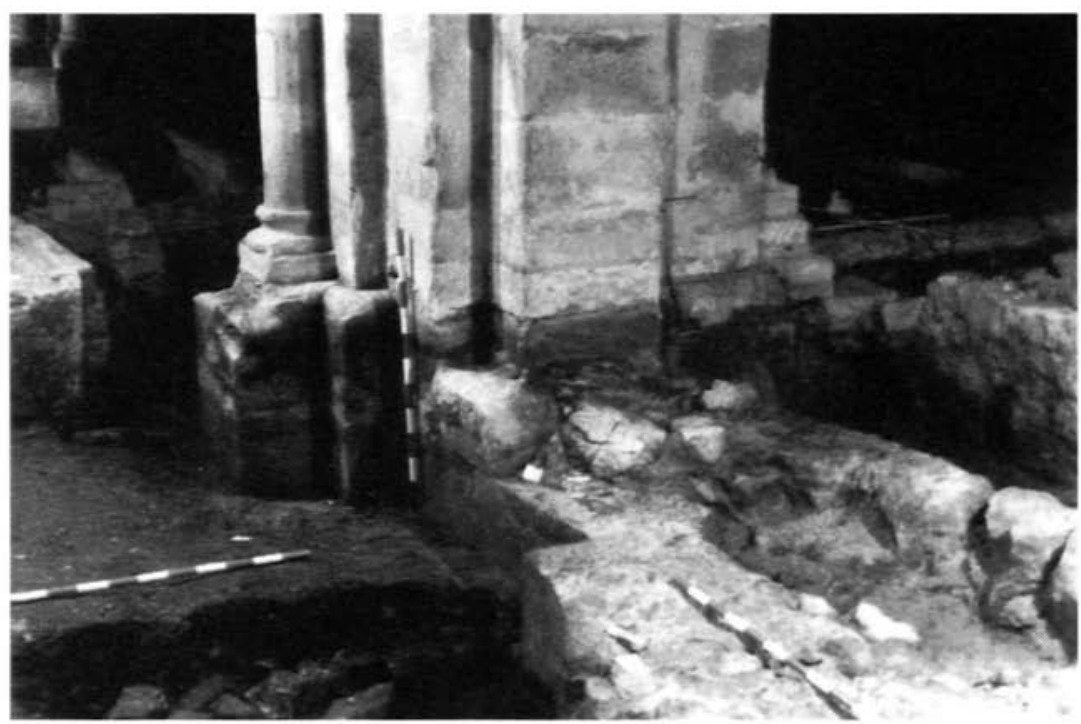

Figura 14. Conexión del áhside lateral sur con el pilar sur del arco triunfal. Foto: P. Matesanz

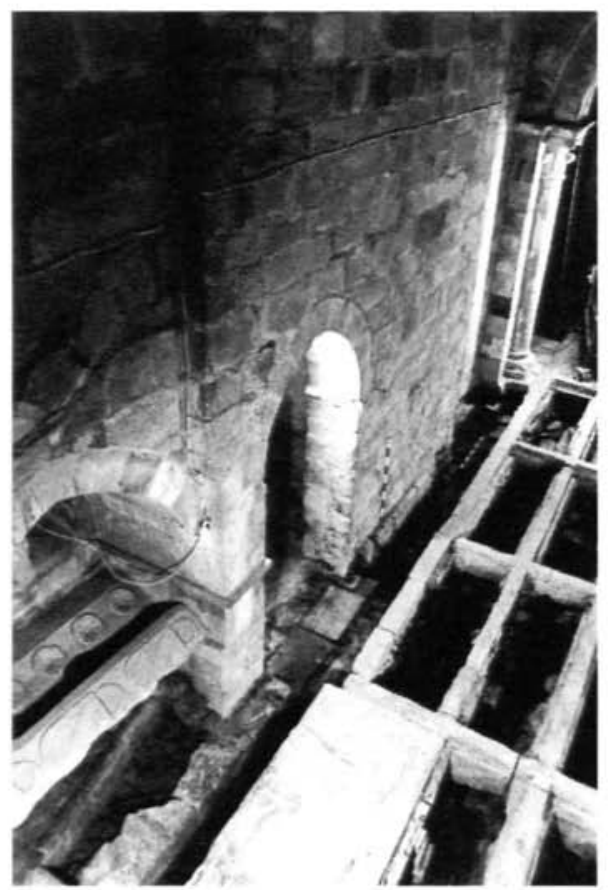

Figura 15. Vista desde el este del paramento sur de la zona B-7. Foto: P. Matesanz 


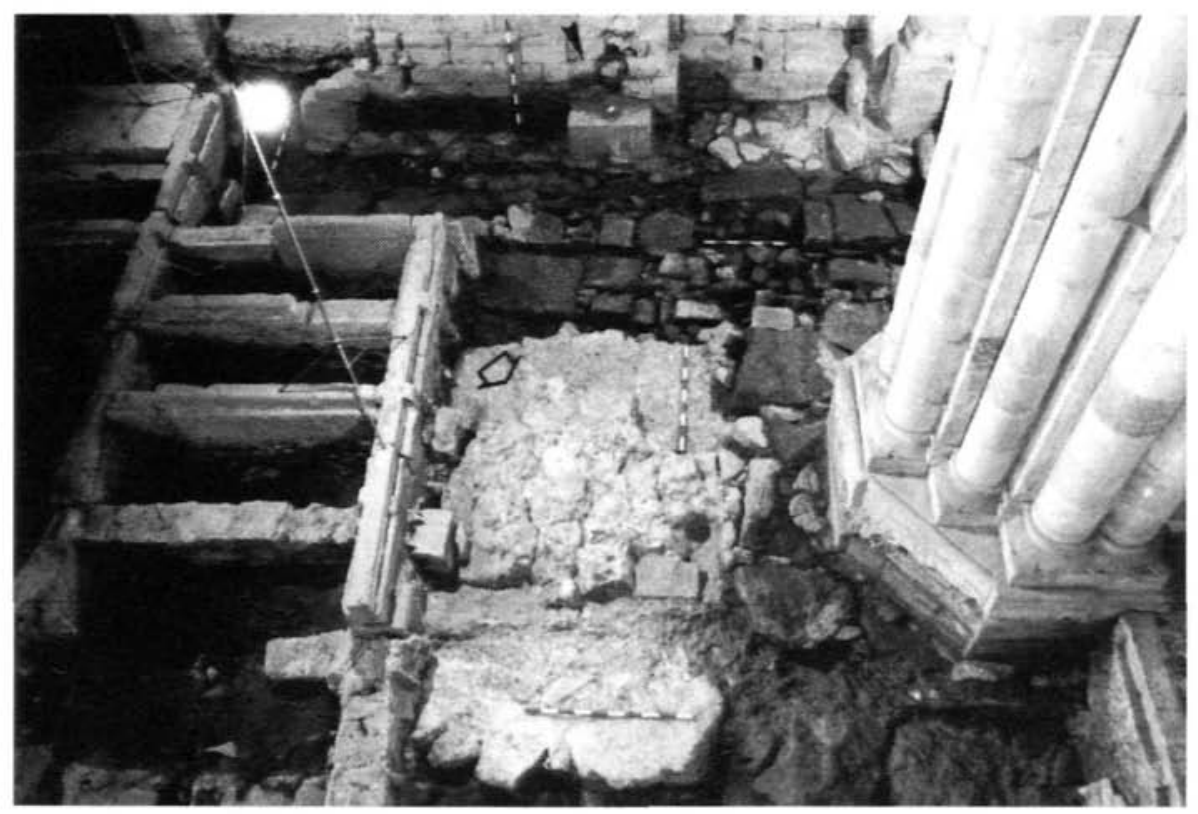

a)

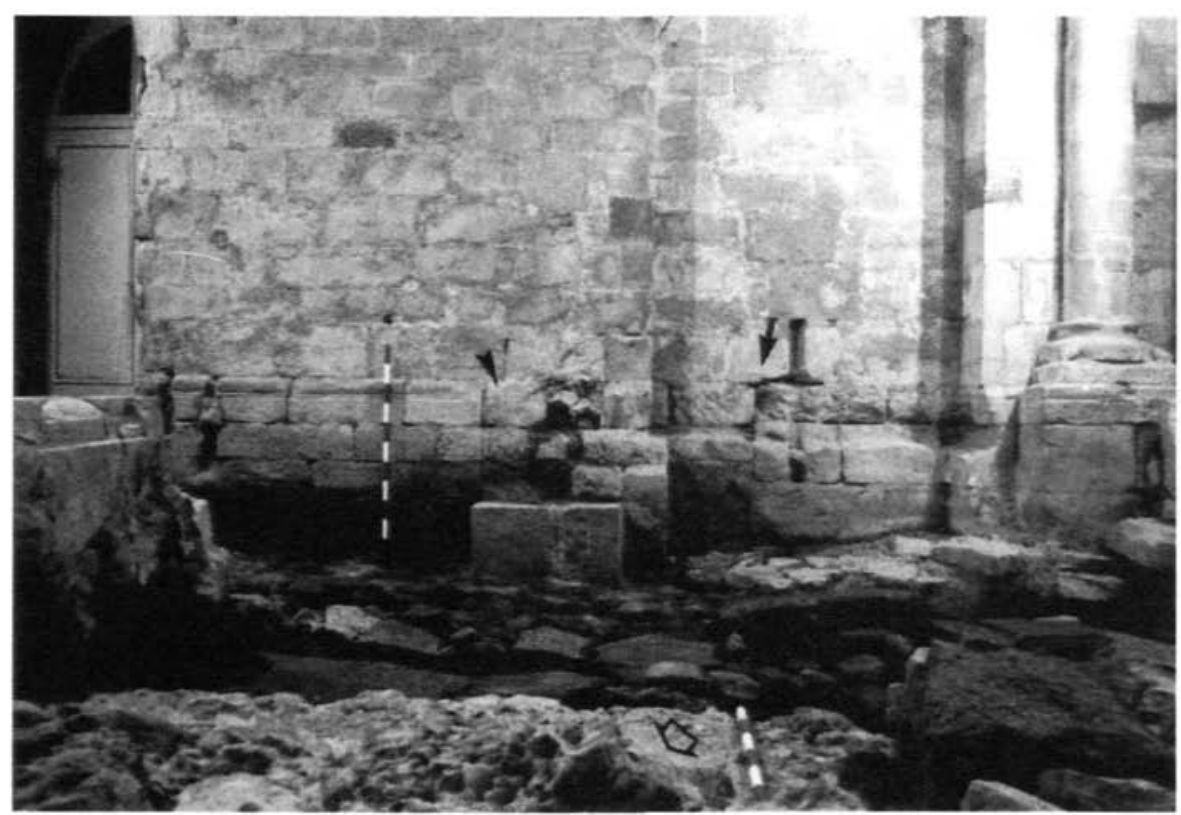

b)

Figura 16. a) Vista general de la zona B-7 desde el norte. Se ve en primer plano la plataforma de cimentación del pilar oeste del arco toral sur de la iglesia románica. b) Detalle del muro sur, en donde se identifica el pilar adosado y la linea de rotura entre la iglesia románica y la premonstratense. Fotos: P. Matesanz 
tuvo que ver las basas originales, así como el arranque de los ábsides, con lo que hay que pensar que o bien no sabía lo que era o bien hizo caso omiso de lo que veía.

El pilar sur del arco triunfal románico también fue transformado para la instalación de las nuevas bóvedas. Aunque la estructura general del pilar es homogénea trabando perfectamente con los ábsides central y sur (Fig. 12b), la intervención de Arenillas abujardando una gran parte de los sillares, hizo que la lectura fuera más complicada.

En el sur, en la zona B-4, se halló el ábside sur de la iglesia románica, pudiéndose comprobar la superposición de los niveles premonstratenses sobre los románicos (Fig. $13 a$ y b). El ábside trababa con el pilar sur, siendo unitario (Fig. 14). También se constató cómo el ábside lateral sur románico encajaba con el pilar adosado al paramento sur (Fig. 13a). No obstante, esta zona también había sido transformada considerablemente durante la intervención restauradora de los años sesenta-setenta; la inclusión de una gran plancha de hormigón había ocultado parte del zócalo del pilar sur del arco triunfal. Desde aquí se pudieron seguir los muros románicos (paramento sur, hacia el oeste) por debajo del arcosolio situado en la zona B-7 (Fig. 8 y Fig. 15). Este arcosolio se ubica junto a una de las puertas de entrada a la iglesia premonstratense, donde fueron localizados también los restos de otra puerta que correspondería a la iglesia románica y que daría pie a una escalera que conduciría a una posible torre. Todo esto explicaría el considerable grosor del muro en esa zona. Más hacia el oeste se descubrió el soporte de un pilar adosado al paramento sur (Fig. 8 y Fig. 16 a y b, con flechas) que se correspondía con la plataforma de cimentación del pilar oeste del arco toral sur (Fig. 8 y Fig. 16a y b con flechas) que, a su vez, se relacionaba con el pilar sur del arco triunfal.

Los restos de la iglesia románica, en el paramento sur, concluyen casi un metro más hacia el oeste, produciéndose el mismo fenómeno que en el norte (zona B-8), con el final de paramento y cimentación según las mismas características descritas anteriormente. En el muro sur la línea de rotura es clara y encaja perfectamente con el cambio de cimentación (Fig. 16b, señalada con una flecha).

\section{CONCLUSIONES}

El monasterio de Santa María la Real es un ejemplo claro de perduración en el tiempo de un complejo monástico. La multitud de intervenciones llevadas a cabo en el mismo, tanto las de época histórica como las más modernas, así nos lo atestiguan. Es un ejemplo también de simbiosis perfecta entre arquitectura y arqueología en cuanto a necesidades mutuas; sirviendo para atestiguar, si bien hay todavía arquitectos que defiendan lo contrario, lo imprescindible que es la intervención arqueológica en edificios de estas características. No obstante, aunque para el arqueólogo es importante el solo hecho de tener cabida en un proyecto como éste, siempre es preferible para él poder realizar su labor en coordinación con el arquitecto, como así se justificaba en la génesis del proyecto. 
Las intervenciones arquitectónicas de los años sesenta y setenta han resultado ser bastante nocivas, especialmente en lo que respecta al edificio en sí, con repercusiones claramente negativas en el subsuelo, como en el caso de la iglesia. La intervención en paramentos también ha sido especialmente perjudicial, insistiendo en la necesidad de un tratamiento lo menos agresivo posible. Obviamente lo ideal es que por sistema todo edificio histórico sometido a intervención arquitectónica fuera analizado previamente y documentado con precisión. Desgraciadamente, esto no siempre se corresponde con la realidad.

En el caso de Aguilar el descubrimiento de una nueva iglesia, gracias a las excavaciones arqueológicas y al análisis de paramentos, nos ha permitido comprobar la importancia de ese análisis de un edificio histórico a dos bandas (arqueología y arquitectura), sin dejar de lado el apoyo de las fuentes documentales, la investigación antropológica y el estudio de los materiales. La iglesia aparecida junto a los restos previos es de una importancia considerable, especialmente por sus características morfológicas (iglesia de tres naves con tres ábsides semicirculares, con transepto pero sin brazos). Los vacíos documentales y la falta de referencias arquitectónicas han sido suplidas por la intervención arqueológica. De todas formas, la no conclusión de los trabajos arqueológicos no nos ha permitido esclarecer ciertas incógnitas, como la configuración generalizada de las estructuras protorrománicas y visigodas o qué ocurre con el cierre por el oeste (si era una iglesia inacabada, si podría haber tenido un cierre provisional, etc.), si sufrió algún proceso destructivo que provocara su reconstrucción, dónde están los elementos decorativos que debería tener, canecillos, capiteles, etc. La no existencia, por el momento, de ábside central de la $1 .^{a}$ iglesia premonstratense nos está indicando que probablemente los premonstratenses utilizaron la cabecera de la iglesia románica hasta que fue cerrada por el ábside gótico de los ss. XIII-XIV.

La constatación de la conexión de los ábsides románicos con los pilares cruciformes que se mantenían in situ y que alojaban los grandes capiteles que hoy día se conservan en el Museo Arqueológico Nacional es de vital importancia para reforzar la datación de la escultura entre 1150 y 1173.

Finalmente queremos insistir en la necesidad de entendimiento y colaboración entre arquitectos y el arqueólogos por el bien del Patrimonio Histórico.

\section{BIBLIOGRAFÍA}

ÄrCHIVO HistóRICO NACIONAL, Sección Clero-Pergaminos: Carpetas 1647 y 1648.

Assas, M. de, 1872: "Monasterio o Abadía de Aguilar de Campoo-, Museo Español de Antigüedades, t. I, 597-620.

BACKMUND, N., 1956: Monasticon Praemonstratense, 3 vols. Strauling. 
Becerro de Aguil.ar de CampoO, Archivo Histórico Nacional, 1. a mitad s. XIII, códice 994-B.

Bravo Juega, M. ${ }^{a}$ I., y Matesanz Vera, P., 1986: Los capiteles del Monasterio de Santa María la Real de Aguilar de Campoo (Palencia) en el Museo Arqueológico Nacional, Salamanca.

CABAllero ZOREDA, L., 1987: "El método arqueológico en la comprensión del edificio (sustrato y estructura)", Curso de Mecánica y Tecnología de los Edificios Antiguos, Madrid, 13-58.

García GuineA, M. A., 1975: El arte románico en Palencia, Palencia.

GOnZÁl.zZ DE FAUVE, M. ${ }^{a}$ E., 1992: La Orden Premonstratense en España. El Monasterio de Santa María de Aguilar de Campoo (Siglos XI-XV), Tomo I: Texto; Tomo II: Documentos, Aguilar de Campoo.

LAMPÉREZ Y ROMEA, V., 1930: Historia de la arquitectura cristiana española en la Edad Media, 3 vols., Bilbao-Madrid-Barcelona.

LATORre González-Moro, P., 1987: "El sitio histórico de Melque (Prov. Toledo). La intervención integrada con una finalidad didáctica", Archeologia e restauro dei monumenti, I Ciclo di Lezioni sulla Ricerca applicata in Archeologia, Certosa di Pontignano (Siena), 157-194.

MATesanz Vera, P., 1992: “The medieval monastery at Aguilar de Campoo, Palencia: archaeology and architecture", Medieval Europe 1992, Religion and belief, Preprinted papers, vol. 6, York, 53-58.

MÉLIDA, J. R., 1915: "El Monasterio de Aguilar de Campoo", Boletín de la Real Academia de la Historia, t. 66, 43-49.

MerChán Fernández, C., 1980: El abadengo de Aguilar de Campoo: el nacimiento del Señorio dominical, Extracto de tesis, Cáceres.

- 1982: Sobre los origenes del régimen señorial en Castilla. El abadengo de Aguilar de Campoo (1020-1369), Málaga.

SAÉnZ DE OIZA, F. J., 1983: -Superposición y adaptación de nuevas estructuras en edificios antiguos", Curso de Mecánica y Tecnología de los Edificios Antiguos, Madrid, 121-136. 